\title{
Cultural Aspects of Organizations Functioning - An International Approach
}

\author{
Agnieszka Rzepka, Ph.D ${ }^{1}$, Andrzej Jan Olak Ph.D. ${ }^{2}$ \\ ${ }^{I}$ Department of Economics and Management of Economy, Lublin University of Technology, Lublin, Poland, \\ ${ }^{2}$ The BronistawMarkiewicz State Higher School of Technology and Economics in Jarostaw, Poland
}

\begin{abstract}
National culture or the culture of social groups has a significant impact on attitudes and behaviors of people in organizations. Each person, at the time of becoming a member of an organization, brings in a massive amount of life experience, own system of values, a set of norms and moral principles, and also shaped perceptions and stereotypes about others. These factors undoubtedly affect the functioning of an organization. Different cultural background may, on the one hand, become the source of problems in human-to-human interaction, but on the other hand, help to build a positive cultural identity, sense of belonging and well-being. The purpose of this article is to present cultural aspects of organizations functioning. This article presents the meaning of "culture" in an organization, different cultural models of an organization, factors which are involved in managing organizational culture, consequences of cultural differentiation, and some cultural interactions and the sources of cultural barriers. Finally, the article presents the outcome of research carried out in three organizations, each located in a different country, to show dependencies between culture and communication problems between employees.
\end{abstract}

Keywords: communication, communication problems, cultural barriers, culture in an organization

\section{Culture in an organization}

The culture of a nation is defined as values, expectations and behaviours learned and shared by a group of people and passed on from generation to generation. Features of national cultures are formed in relation to historical, geographical and economic factors. In tradition, religion and language we may trace the sources of shared values, norms, behaviours and meanings. Defining and identifying cultural patterns allows to move in the society [1].

There are many factors which externally influence an organization. Radosław Wolniak distinguishes few levels of culture from which the culture of a nation and a community culture of a particular region are on top. Then, there is an organizational culture of a company and finally, a professional culture [2].

Culture as a product of three interrelated aspects: psychological, that covers individual and group attitudes, perceptions and values, behavioural and situational has not been given by nature. It is a product of human activity, patterns of behaviours and interactions shared by groups of people. People share culture by following patters of behaviour and knowledge acquired in educational process. For an organization, if a culture is treated as knowledge, organizational processes and institutional practices and traditions, the process of sharing them would involve storing and communicating the achievements of a given organization. Within this meaning, a culture would be a reservoir of knowledge accumulated by those who had been working in the organization before we were employed. A kind of legacy in a form of collective memory.

However, this reservoir, in case of an organization, is a highly flexible structure. In every day activities people perform in an organization they follow invented, discovered and developed organizational patterns and share institutional beliefs, but at the same time, they individually introduce their own values, norms, languages, attitudes and personalities to things they do causing that single and, in a longer perspective general, principles and practices of the whole organization change [3]. Culture in an organization is a phenomenon which consists of two layers: a core of an organization formed by the solid mission and vision of the management expressed by commitment to perform certain tasks and, a supportive layer with all organizational values and practices shared by people. The two layers influence each other. Moreover, human factor is influenced externally by all cultural layers of the society and the community to which he or she belongs. Therefore, the problems in human-tohuman behaviour in an organization may be the outcome of problems on national, regional, ethnic, gender, generational, and a social class plane [4].

Publications about culture in an organization intensified in the twentieth century, but some theories already appeared in the 30s of the last century. For example, Chester Barnard, the author of pioneering work in management theory and organizational studies, stated that one of the three basic functions of management is to formulate, define, and inculcate a common purpose that gives meaning to the organization. Managers determine what is important, what organizational members should pay attention to, and the meaning of cultural values for daily behaviour. They also create and sustain a culture by role modelling, by showing what behaviours are 
acceptable in the culture, and what are not acceptable. In the management sciences this is known as the "cultural perspective of organizational behaviour [5] ".

Cultural perspective is made up of three elements which together make up the core of an organization's culture: the mission, the values and commitment that develop within an organization. These three elements are interrelated and so must be aligned in order to form a consistent culture. This model was presented in Figure 1 [6].

Figure 1. Cultural perspective in an organization

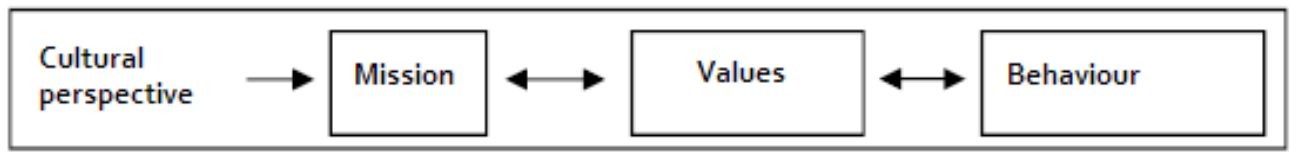

Source: P. Cardona, C. Rey, Management by Missions, p.33.

The cultural perspective aims to generate what may be termed "ownership" or a sense of belonging. Ownership goes beyond empowerment. Many companies that have launched empowerment programs find that the difficult thing is not giving people more power but gaining their commitment. To do this companies must develop a culture that persuades people to identify with a shared undertaking and a shared value.

The role of cultural perspective is to create conditions to identify with an organization. It is not an easy task as the management must create models and symbols that reinforce desired values, a certain philosophy that gives meaning to business enterprise. Important also are internal communication departments and systems which spread these philosophies throughout the organization. Always efforts to obtain employee identification are backed up by top management and reinforced by internal communication campaigns

\section{Cultural models in an organization}

There may be distinguished several levels of culture which may have an impact on an organization functioning. The term level is the degree to which the cultural phenomenon is visible to the observer. Edgan Shein in his book on organizational culture and leadership gave the background for further considerations worldwide. He divided the levels into three: "artifacts (visible organizational structures and processes), espoused beliefs and values (strategies, goals, philosophies) and underlying assumptions (unconscious, taken-for grated beliefs, perceptions, thoughts and feelings) [7] ".

Debra L.Nelson further explains his theory. She writes that they key to understanding culture through artifacts lies in figuring out what they mean. Among the artifacts of culture are personal enactment, ceremonies and rites, stories, rituals and symbols. Assumptions in her opinion are the deeply held beliefs that guide behaviour and tell members of organization how to perceive and think about things. The third level is almost unconscious and invisible. It includes environmental and human relationship [8].

More and more significant in the theory of management become cultural models. They are defined as "beliefs, values and ideology which are at the heart of organizations. Individuals hold certain ideas and valuepreferences which influence how they behave and how they view the behaviour of other members. These norms become shared traditions which are communicated within a group and are reinforced by symbols and rituals [9]".

The developing interest in cultural models arises mainly from a wish to understand and operate more effectively within this domain of values and beliefs of members of an organization. A worldwide research in the area of culture and management was made by Geert Hofstede who developed a dimensional approach to crosscultural comparisons as a result of studies into national cultural differences. He based the research on surveys conducted among hundreds of employees in more than fifty countries and distinguished five main dimensions of national cultures [10]:

\section{Relation towards individuals}

a) individualism - in this dimension the interests of an individual are most important (it is present in France, Italy, Belgium, Great Britain, Norway, USA).

b) collectivism, where the priority is the interest of a group (it appears in countries such as Ecuador, Columbus, Venezuela, Panama, Mexico, Greece, Japan).

In countries where the individual-oriented approach dominates members of the society define themselves as people who need to take care of their interests by themselves. Therefore, appreciated is the autonomy of individual achievements and privacy. On the other hand, in countries were collectivism dominates members of such a culture define their existence as part of a group. The group takes care about interests of individuals and requires loyalty. 


\section{Relation towards authority}

a) countries which respect authority (these countries include France, Belgium, Italy, Mexico, Panama, Japan)

b) countries which do not respect authority (these are countries such as Finland, Norway, Canada, United Kingdom, USA, Denmark).

In countries which respect authority, people appreciate those on managerial positions. They take into account and recognize decisions taken by the management in an organization. In countries where the authority is respected people aim at the pursuit of equality and partnership in human relation, and symptoms of hierarchy are often perceived in a negative way. In organizations where the authority is not respected is more difficult to manage human capital and managers have to win the recognition through their behaviour and actions.

\section{Relation towards uncertainty}

a) countries that accept uncertainty (they include Sweden, Norway, USA, United Kingdom, Canada and Australia)

b) countries that avoid uncertainty (this attitude is present in France, Portugal, Brazil, Panama, Greece, Japan). Changes in an organization are much easier to carry out in countries with a high level of acceptance of uncertainty. People who come from such cultures are willing to take risks. In turn, the communities that avoid uncertainty will be oriented on creating procedures in an organization.

\section{Relation towards time}

a) short-term model of culture (present in Pakistan, Nigeria, the Philippines, Canada, UK, USA)

b) long-term model of culture (present in China, Taiwan, Japan, Brazil, India, South Korea).

In the model of cultures of short-term attitude, their representatives expect immediate effects of actions they undertake. In contrast, in long-term model of culture, people are used to wait for the results of their work for a long time [11].

\section{Consequences of cultural differentiation}

Dissimilarities between people may be consequences of different national origin. They often cause that chosen collective duties, tasks, processes may be understood, fulfilled and managed contrastively [12]. What is more, people may perceive requirements, claims and a small-talks in a different way. The same applies to co-members and leaders. If members of an organization come from different countries they will have a different attitude towards they partners and supervisors. To give an example, problematic may be the perception of the role of a leader, skills and qualifications he or she should have as well as features of character. For the Japanese a person on a managerial position should have both theoretical and practical skills. For the Italians, features of character are important. A manager should have a dominant personality and the ability to influence others working within an organization. Koreans will not accept a partnership relationship management style [13]. Cultural dissimilarities manifest themselves also in a problem of the hierarchy in an organization, its structure. It is visible in determining and fulfilling social roles or assignment of tasks [14].

Furthermore, people from different cultures organize meetings in a different way. It is visible while setting working hours, duration of a meeting and its place, arrangement of a place, the course of a meeting, preparing and observing the program of a meeting. To give an example, Englishmen pay great attention to punctuality. They always are on time and stay at the meeting till its very end. The French, on the contrary, keep a distance to being punctual, however they pay attention to clothing, documentation, they do not want to stay on a business meeting longer that hour and a half.

Cultural disparities may be observed during the process of problem solving or undertaking decisions. In this case, depending on nationality, decisions can be made by voting, negotiation, or reaching agreement collectively or by a manager him or herself based on the opinion of other members of an organization. While solving a problem people may count on facts, not the opinions, they may use resources to analyse the cause of a problem, or through analysis come from details to general conclusions.

Culture also influences knowledge management and, in particular, knowledge sharing. There are two fundamental approaches to knowledge management: the process approach and the practice approach. Organizations adopting the process approach may implement explicit policies governing how knowledge is to be collected, stored, and disseminated throughout the organization. In contrast, the practice approach to knowledge management assumes that a great deal of organizational knowledge is tacit in nature and that formal controls, processes, and technologies are not suitable for transmitting this type of understanding. Organizational culture influences knowledge management approaches through its influence on individualism vs. cooperativism, it also causes the migration of knowledge. Specific knowledge management behaviours such as ownership and maintenance of knowledge, knowledge sharing, and knowledge reuse seem to be influenced largely by the individualistic or cooperative nature of the culture [15]. Recent investigations regarding cooperative alliances have proved that it is more to share tacit knowledge in a common corporate culture than 
sharing a common national culture. For this reason it is to comprehend the various degrees of cultural tension, so knowledge can be effectively transferred between organizations and possible halts or delays can be prevented [16]. Greater diversity of employees causes more specific challenges and especially communication problems, including misunderstanding among employees and managers and the need to translate verbal and written material into several languages.Cultural differences may be problematic between companies and also they may cause significant problems for the management.

\section{Cultural barriers in organization management}

A culturally diverse organization raises some problems for the management. First of them is a problem of dominance. Sometimes one culture may become dominant. People may start to impose their point of view on others from the minority. Problems of dominance become visible while implementing joint ventures as the cultural majority may impose their solutions and hinder cooperation.

Second barrier lies in avoidance-approach of the management. As it was stressed, different nationalities in one place mean that there is very probable that conflicts will occur. Managers in avoiding problem solving keep the organization at its same, stable level. As it is stressed in literature "many organizational cultures place a premium on conflicts avoidance [17]". However today, an emphasis should be paid on a genuine collaboration, creative dialogue regarding problems, honest and empathetic leadership in addressing and responding to conflicts and preventative, persistent and systemic approaches to resolution.

Thirdly, the problem of communication barriers occur. Barriers can be categorized as those at exist at the individual level and those that exist at organizational level. Organizational barriers pertain to factors for the organization as a whole. One of the most significant barriers relates to status and power differences. Low-power people are reluctant to communicate with upper-management and the latter may think that low-status people have little to contribute. There may be differences across departments in terms of goals. Each department may perceive problems in its own way being reluctant to be concerned with problems of the other departments. Communication effectiveness is hindered by the absence of formal channels in an organization. Organization must provide upward, downward and horizontal communication channels in order to be communicative as a whole. Finally, communication flow may not fit the team's organization's tasks. If a centralized communication structure is used for non-routine tasks, not enough information will be circulated to solve problems.

Table 1. Communication barriers and ways to overcome them

\begin{tabular}{|c|c|}
\hline Barriers & How to Overcome \\
\hline $\begin{array}{l}\text { Individual } \\
\text { Interpersonal dynamics } \\
\text { Channels and media } \\
\text { Semantics } \\
\text { Inconsistent cues }\end{array}$ & $\begin{array}{l}\text { Active listening } \\
\text { Selection of appropriate channel } \\
\text { Knowledge of other's perspective } \\
\text { MBWA }\end{array}$ \\
\hline $\begin{array}{l}\text { Organizational } \\
\text { Status and power differences } \\
\text { Departmental needs and goals } \\
\text { Lack of formal channels } \\
\text { Communication network unsuited to task } \\
\text { Poor coordination }\end{array}$ & $\begin{array}{l}\text { Climate of trust, Dialogue } \\
\text { Development and use of formal channels } \\
\text { Encouragement of multiple channels, formal } \\
\text { and informal } \\
\text { Changing organization or group structure } \\
\text { to fit communication needs } \\
\text { Feedback and learning }\end{array}$ \\
\hline
\end{tabular}

Source: R. Daft, D. Marcic, Understanding Management, Gengage learning, Mason, USA, 2006, p.507

In case of existence of differences in language skills or lack of fluency in the official language of an organization, the employees may hider their own fear behind the "curtain" of cultural diversity. If the management organizes meetings during which lectures or discussions are avoided and employees have no intention to learn foreign language or to participate in language trainings the whole organization may suffer from it. Conversations in a native language during official meeting or preparing documentation in other language than officially used in an organization should be avoided as it leads to dispersion of the organization's unity, incoherence of decisions and undermining of mutual trust between the employers and management [18].

Communication tools vary and sometimes the management may use them inappropriately. Members of an organization often use the latest technological solutions only to avoid direct contacts with co-members from a different country. If writing and using IT language solutions than speaking between the members of one group is preferred, people would not see the need of learning. In a long-term perspective the effectiveness of such a group may be lower than other groups in which greater attention is paid to oral communication. Written language leads to the decrease in engagement in cooperation and willingness to organize joint initiatives [19]. Sometimes, the management focuses too hard on accomplishment of goals paying no or little attention to the 
way of accomplishing them. If the management uses available patterns and recommendations without searching for new solutions, it will be very difficult for the whole organization to develop. Cultural models and organizational models should always be considered while entrusting tasks in a culturally diversified working environment. The management should always observe and control group work, analyse processes, determine rules necessary to improve the organization's functioning so that to bring it benefits.

In inter-cultural relations participate people who represent different nationalities or organizational cultures. They present their own system of attitudes, perceptions, motivations and features. It should be borne in mind that human resources give shape the inter-organizational interactions. People representing different cultures and nationalities exhibit certain behaviours in inter-cultural contacts, which in turn modify their future behaviours. These behaviours are a kind of cultural barriers. Generally, such barriers can be divided into:

1. Barriers arising from distinctiveness of national cultures.

2. Organizational barrier

3. Barriers rooted in an individual.

A key cultural barrier, resulting from the diversity of national cultures, is the cultural distance, resulting in culture shock. It is manifested in negative attitudes towards a new culture and its members. This cultural shock is highly undesirable as it reduces the efficiency of the man who experiences it, and also interferes with interpersonal relationships.

Many negative consequences causes cultural ethnocentrism which leads to an excessive conformity within a group. In addition, it results in a reluctance to contact with representatives of other cultures, discrimination, the tendency to impose own patterns. It has been observed that ethnocentrism on the national level may lead to the disclosure of ethnocentrism of organizations and individuals. It may create serious subsequent cultural barriers.

\section{Communication in organization in different countries - an empirical approach}

Employees of an Institute of Economy and Management of a University in Poland carried out research on cultural determinants of organizations functioning. The research has been carried out in Polish, Ukrainian and Dutch companies. The research tool was a questionnaire for the employers of organizations and aimed at extracting cultural models in organizations and showing dependencies between communication styles and country of origin of an organization.

The results of the research proved that in Poland and Ukraine still there is an approach in which the interest of a group precedes the interest of an individual. A totally different situation is in the Netherlands. There, far more important is a vision and action of a single human being whose autonomy and achievements are appreciated.

In Polish and Ukrainian companies, members of a group are unwilling to perform tasks they do not know, they fear instability and uncertainty. On the other hand, it has been observed that in the Dutch organization people are willing to undertake risks and new duties.As far as the attitude towards management is concerned, in Polish and Ukrainian organizations people respect leadership whereas in the Netherlands visible is a tendency to strive for equality and partnership in "superordinate-subordinate line".

Interesting is also the outcome of dependencies between communication problems and the country of origin. The questionnaire included questions concerning communication problems such as: prejudging the speaker and another common reason for being interrupted - not keeping eye contact. Furthermore, people were asked about frequency of occurrence of communication problems: engagement in a tense or emotionally charged conversation, criticism, threats, change of a subject, insulting and telling commands. These dependencies were shown in table 2 and figure $2-8$.

The research outcome shown differences between organizations in the Netherlands, Poland and Ukraine. In each of the analysed organizations communications problem occur, however, the frequency of their occurrence varies significantly. ( $p$-value $<\alpha, p=0,00003$ ). The least frequently they occur in the Netherlands as almost half of the respondents marked an answer "never" and 17\% "once a week". In Poland also a high number of respondents do not have communication problems at work- $37 \%$ and around $40 \%$ just "once a week". The worst situation occurs in Ukraine where every third participant of the research has a problem "once a week" and $16 \%$ even a few times a day.

Table 2. Results of Pearson's chi-squared test. Country, sex, age and education and communication problems

\begin{tabular}{|l|l|l|l|l|}
\hline & Country & Sex & Age & Education \\
\hline Communication problems & $0,00003^{* * *}$ & $0,04858^{*}$ & $0,00006^{* * *}$ & $0,01846^{*}$ \\
\hline Applied method & $0,00002^{* * *}$ & $0,00340^{* *}$ & $0,00056^{* * *}$ & $0,00000^{* * *}$ \\
\hline People of the same sex & 0,59441 & $0,00572^{* *}$ & $0,00205^{* *}$ & $0,01017^{*}$ \\
\hline Meaning of age & $0,03905^{*}$ & 0,49277 & 0,08740 & 0,35874 \\
\hline Eye-contact & $0,00000^{* * *}$ & 0,35480 & $0,00582^{* *}$ & $0,00016^{* * *}$ \\
\hline Prejudging the speaker & 0,07244 & $0,00907 * *$ & $0,04582^{*}$ & 0,86764 \\
\hline
\end{tabular}


Cultural aspects of organizations functioning - an international approach

Source: Own research

\begin{tabular}{|l|l|l|l|l|}
\hline $\begin{array}{l}\text { Influence of emotions on } \\
\text { conversation }\end{array}$ & 0,09576 & $0,00045^{* * * *}$ & $0,00105^{* *}$ & 0,15540 \\
\hline Criticism & $0,00095^{* * *}$ & $0,04830^{*}$ & 0,26708 & 0,36951 \\
\hline Threats & $0,00000^{* * *}$ & 0,12546 & $0,00011^{* * *} *$ & $0,00062^{* * *}$ \\
\hline Change of a subject & $0,00000^{*} * *$ & 0,16785 & 0,05783 & 0,12698 \\
\hline Insulting & $0,00000^{*} * *$ & $0,01506^{*}$ & $0,01186^{*}$ & $0,00425^{* *}$ \\
\hline Telling commands & $0,00000^{*} * *$ & 0,09102 & $0,00049^{*} * *$ & 0,26966 \\
\hline
\end{tabular}

Figure 2. Occurrence of communication problems

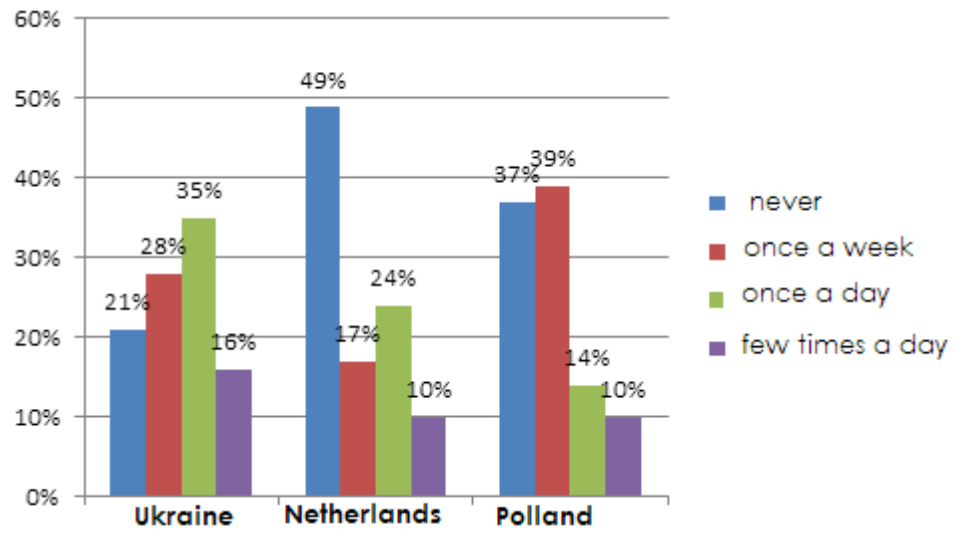

Source: Own research

Each country varied also in terms of methods applied to solve communication problems. $\mathrm{p}<\alpha$, $(\mathrm{p}=0,00002)$. In all countries the most often applied methods were cooperation and compromise. In the Netherlands "cooperation" is used the most frequently - 58\%, similarity frequently it is used in Poland - $40 \%$. "Compromise" is used in all countries at the similar level- around $30 \%$ of the respondents marked this answer. In Ukraine a large number of respondents indicated "submissiveness" (23\%) whereas in the Netherlands only 3 $\%$ of respondents admitted that submissiveness exists in their organization as a method to solve problems. In Poland there may be observed the highest percentage of people who stated that "avoidance" is used by the management to solve problems.

Figure 3. Method used to solve communication problems at a workplace grouped according to country of origin

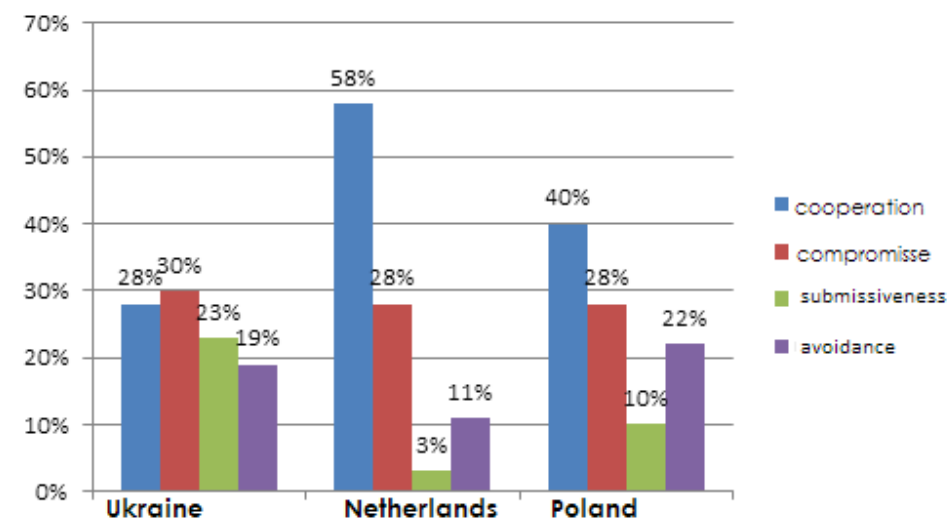

Source: Own research

Our eyes also reflect our sincerity, integrity and comfort when communicating with another person which is why having good eye contact while conversing is the indication that the communication has gone on well. If a listener keeps an eye contact it means he or she is active, eyes are a way of building connection with the other person and trust. Participants in a conversation and members of different organizations do pay attention to the behaviour of a listener or business partner. The outcome of the research showed differences between particular countries and their attitude towards keeping an eye contact $p<\alpha(p=0,0000)$ and the meaning of an age of the interlocutor $\mathrm{p}<\alpha(\mathrm{p}=0,03905)$. Respondents from Ukraine were least particular about keeping an eye contact $(79 \%)$, a slightly higher result was reached in case of the respondents from the Netherlands. 
However, all the respondents from Poland pay a great attention to it. (100\%) The meaning of an age of the interlocutor was also the highest for the respondents from Poland $-52 \%$, and the lowest for the respondents from Ukraine (35\%).

Figure 4. Factors which have an impact on communication grouped according to country of origin

\section{Source: Own research}

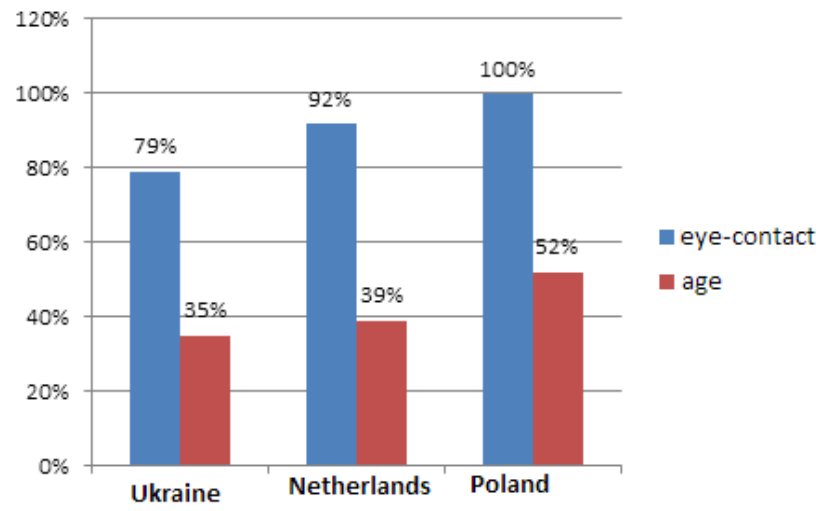

In organizations also some negative events occur and sometimes they may influence they way people speak to each other. Countries vary both in respect of the frequency of the occurrence of negative conversations at work: criticism $\mathrm{p}<\alpha(\mathrm{p}=0,00095)$, threats $\mathrm{p}<\alpha(\mathrm{p}=0,00000)$, change of a subject $\mathrm{p}<\alpha(\mathrm{p}=0,00000)$, insulting $\mathrm{p}<\alpha(\mathrm{p}=0,00000)$ and telling commands $\mathrm{p}<\alpha(\mathrm{p}=0,00000)$. The highest percentage of respondents met with criticism in the Netherlands $(11 \%)$ and in Poland - every third person indicated such an answer.

Figure 5. Percentage of respondents who have contact with criticism

Source: Own research

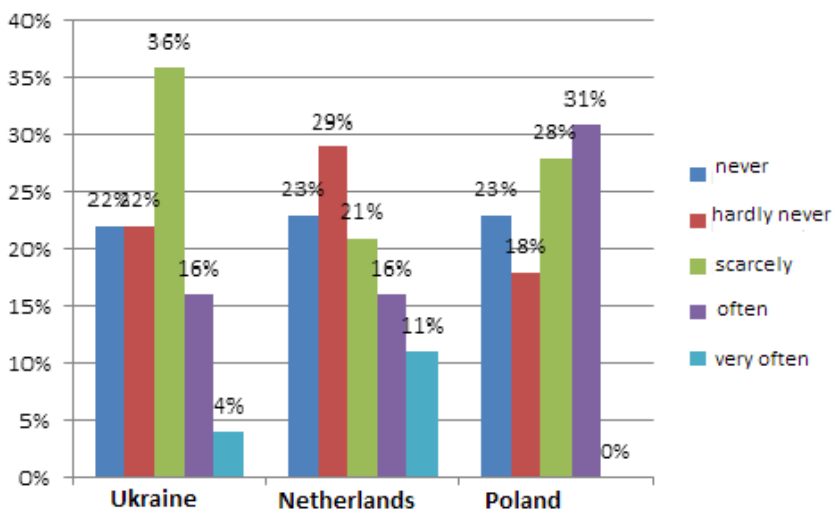

The highest percentage of respondents who had no contact with threats is in Poland, slightly lower is in the Netherlands $40 \%$. Most frequently spoken threats occur in Ukraine.

Figure 6. Percentage of respondents who have contact with threats

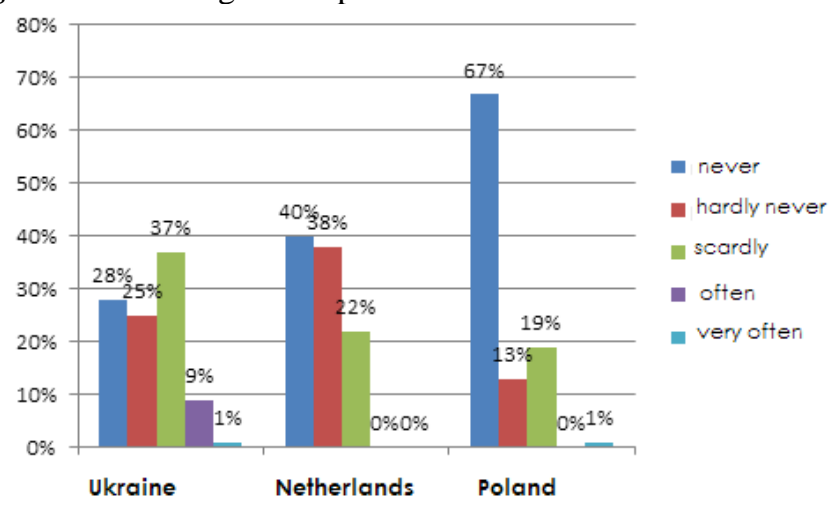

Source: Own research 
Change of a subject during conversation most frequently occurs in Ukraine. $5 \%$ of the respondents indicated an answer "very often", and $28 \%$ an an answer "often". In Netherlands, a conversation is interrupted in the same way but less often. In Polish company a "change of a subject" occurs the least frequently.

Figure 7. Percentage of respondents who have contact with change of a subject

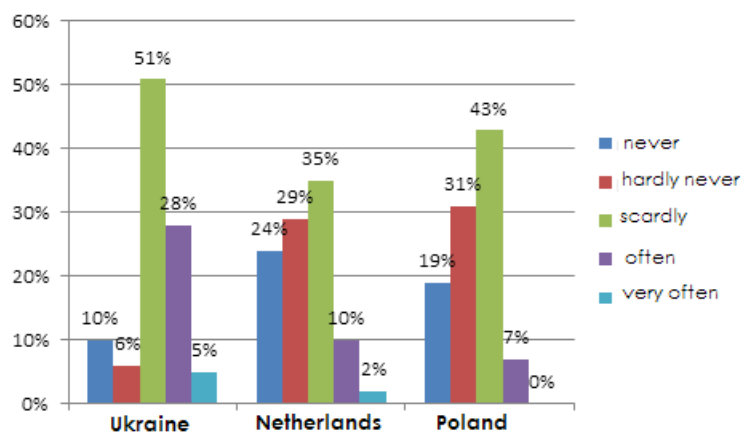

Source: Own research

It is very offensive when someone throws an insult somebody's way. And if it happens at work a person may be even more seriously hurt. Insults are observed the most often in Ukraine - $22 \%$ of the respondents noticed such a behaviour "often", and $8 \%$ "very often", 44\% "scarcely". More than half of the respondents from Poland indicated answer "never" and a slightly lower percentage marked the same answer in the Netherlands.

Figure 8. Percentage of respondents who have contact with commands

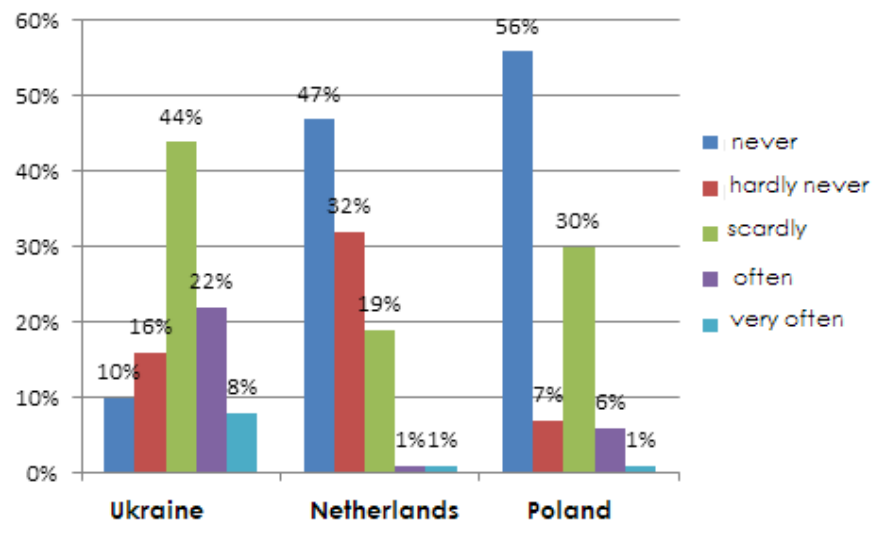

Source: Own research

"Telling commands" occurs "very often" and "often" in Ukraine, whereas respondents from Poland and the Netherlands meet such a behaviour "never" or "hardly ever".

\section{Conclusion}

Managers of today are advised that "cultural understanding may minimize the impact of culture shock and maximize inter-cultural experiences as well as increase professional development and organizational effectiveness. Cultural sensitivity should teach managers that culture and behaviour are relative and that managers should be more tentative and less absolute in human interaction [20] '.

The effectiveness of management may be hindered by cultural differences and unique national attitudes and values. The cultural models discussed in this article show that organizations must be especially sensitive to patterns of behaviour, styles and understanding of processes implemented by organizations.

The role of a inter-cultural managers has evolved. For contemporary organizations "cultural difference cannot be seen as an obstacle but a challenge to achieve corporate goals [21] ". Differences between between national cultures can now be seen as potentially valuable sources in the articulation of a global organizational culture. Inter - cultural manager, therefore, has a new multi-layered role as culture management is now far more complex, multifarious and interactive domain. Managing the global workforce requires diversification of human resource practices and strategies. The research proved that although cultural differences create problems in communication plane, they do not cross out the chances of an organization to achieve success. The solution to this problem is knowledge, therefore, education of managers in this field is necessary, especially on managing international communication misunderstandings, and values, beliefs and culture of other nations. 


\section{References}

[1]. M. Rozkwitalska: Bariery w zarządzaniu międzykulturowym. Wolters Kluwer Polska, Warsaw 2011, p. 59.

[2]. R. Wolniak: Wymiary kulturowe polskich organizacji a doskonalenie zarządzanie jakością. Ce-DeWu, Warsaw 2012, p. 89.

[3]. D. Latusek: Rola kultury organizacyjnej w zarządzaniu wiedzą. Wydawnictwa Akademickie i Profesjonalne, Warsaw 2008, p. 170 .

[4]. M. Rozkwitalska: Bariery w zarządzaniu międzykulturowym. Wolters Kluwer Polska, Warsaw 2011, p. 59.

[5]. P. Cardona, C. Ray: Management by missions, Palgrave Macmillan, New York 2008, p.39

[6]. P. Cardona, C. Ray: Management by missions, Palgrave Macmillan, NY 2008, p.33.

[7]. E.H.Shein: Organizational culture and leadership, Wiley and Sons, San Fransisco 200, p.26

[8]. D.L.Nelson, J.C.Quick: Organizational behavior, Science, the real World and You, Cengage learning, Boston, 2013 , p.244.

[9]. T.Bush: Theories of Educational Leadership and Management, SAGE Publications Ltd University of Warwick, UK, London 2003, p.171.

[10]. G. Aniszewska: Kultura organizacyjna w zarządzaniu. Polskie Wydawnictwo Ekonomiczne, Warsaw 2007 , p. 41.

[11]. G. Aniszewska: Op. cit.p . 44

[12]. M. Berger: Going global: implications for communication and leadership training. „Industrial and Commercial Training” 1998, No 4, s. 125-127; J.M. Werner: Managing a Multicultural Team. „B\&E Review” 1995, No 3, p. 16-17.

[13]. C. Heimer, R. Vince: Sustainable learning and change in international teams: from imperceptible behaviour

[14]. to rigorous practice, „Leadership \& Organization Development Journal” 1998, No. 2, p. 84.

[15]. I. Nonaka, H. Takeuchi: Kreowanie wiedzy w organizacji. Placet, Warsaw 2000, p. 235-237.

[16]. D. Leidner, M. Alavi, T. Kayworth: The Role of Culture in Knowledge Management: A Case Study of Two Global Firms, International Journal of e-Collaboration, 2(1), 17-40, January-March 2006.

[17]. M. Del Giudice, E.G. Carayannis, M. R. Della Peruta: Cross-Cultural Knowledge Management

[18]. Fostering Innovation and Collaboration Inside the Multicultural Enterprise, Springer, New York 2012, p.154

[19]. K. Cloke, J. Goldsmith: Resolving Conflicts at Work: Eight Strategies for Everyone on the Job, Jossey-Bass, San Fransisco, USA, $2005, \mathrm{p} 2$.

[20]. I. I. Nonaka, H. Takeuchi: Kreowanie wiedzy w organizacji. Placet, Warszawa 2000, p. 235-237.

[21]. M. Rozkwitalska; Op. cit., p. 90.

[22]. R.T.Moran, P.R.Harris, S.V.Morran, Managing Cultural differences, Leadership skills and strateies for working in a global world, Elsevier Inc, Burlington MA, USA, p.185.

[23]. The Routledge Companion to Cross-Cultural Management, ed. N. Holden, S. Michailova, S. Tietze, Rouletge, NY 2015, p.25. 